\title{
THE CULTURAL ROOTS OF COMPOSITIONAL CAPABILITY IN CHINA: \\ BALANCED MODERATION
}

\author{
Steven Shijin Zhou \\ Nottingham University Business School China, University of Nottingham Ningbo China \\ 199 Taikang East Road, Ningbo, China. 315100 \\ steven.zhou@nottingham.edu.cn \\ Peter Ping Li \\ Nottingham University Business School China, University of Nottingham Ningbo China \\ 199 Taikang East Road, Ningbo, China. 315100 \\ Centre for Creative Leadership (CCL), Shanghai, China \\ Yongda International Tower, Suite 901, 2277 Longyang Road, Pudong, Shanghai. 201204 \\ Copenhagen Business School \\ Frederiksberg, Copenhagen, Denmark \\ peter.li@nottingham.edu.cn

\begin{abstract}
Abby Jingzi Zhou ${ }^{1}$
Nottingham University Business School China, University of Nottingham Ningbo China 199 Taikang East Road, Ningbo, China. 315100

Tel. + (86)-574 8818-0000

abby.zhou@nottingham.edu.cn
\end{abstract}

Shameen Prashantham

China Europe International Business School (CEIBS)

699 Hongfeng Road, Pudong, Shanghai, China. 201206

sprashantham@ceibs.edu

\begin{abstract}
Acknowledgement
The authors would like to acknowledge the financial support from National Natural Science Foundation of China (Grant No. 71732007). We thank Professor Mike Peng (Consulting Editor) and two anonymous reviewers for constructive guidance. We are grateful to Professor Arie Lewin, Professor Martin Lockett and Dr. Yi Ruan for their valuable comments of previous versions of the paper.
\end{abstract}

${ }^{1}$ Corresponding Author 


\title{
THE CULTURAL ROOTS OF COMPOSITIONAL CAPABILITY IN CHINA: BALANCED MODERATION
}

\begin{abstract}
A large number of Chinese firms lack the resources for having competitive advantages. Under this severe constraint, such firms are forced to find new paths toward developing certain competitive advantages, including the ability to combine ordinary resources into novel competitive advantages, which is referred to as compositional capability. Such a special capability underlying novel competitive advantages is related to certain cultural factors, such as the Chinese cultural tradition in the case of China. However, the potential links between compositional capability and the Chinese cultural tradition remain poorly understood and largely unspecified. This paper responds to the call for more research on identifying relevant cultural factors by explicating the inherent connections between compositional capability and the Chinese cultural value of balanced moderation.
\end{abstract}

KEYWORDS: Compositional Capability; Cultural Root; Balanced Moderation; China 


\section{Introduction}

A large number of Chinese firms have succeeded in creating novel competitive advantages from their severe lack of resources in the dynamic context of China (Luo \& Child, 2015; Zhu, Wittmann, \& Peng, 2012). As the composition-based view (CBV) suggests (Luo \& Child, 2015: 389), many Chinese firms are particularly good at leveraging ordinary resources to produce extraordinary results by applying compositional capability, which refers to the extent to which firms are "able to synthesize and integrate disparate resources, including the open resources available to them." Hence, these firms are able to achieve an effective balance between imitation and innovation and between cost and value for high value-price ratios by combining ordinary resources into extraordinary competitive advantages, parallel to the macro-level transformation of China from a low-cost manufacturing base to a high-value innovation economy (Luo \& Child, 2015; Keane, 2007; Kim, 1997; Koh, 2000; Meyer, 2008).

However, while the CBV sheds useful light on how compositional capability helps in shaping compositional competition and orchestrating compositional offerings, an interesting but underexplored aspect of the CBV pertains to its cultural roots. Institutions (both formal and informal) play important roles in shaping the capabilities of firms (Peng \& Heath, 1996; Peng, Lee, \& Wang, 2005). This paper adopts the perspective of viewing culture as a part of informal institutions and attempts to explore its role in influencing the compositional capability of firms in China. Although Luo and Child (2015) suggest that the compositional capability of Chinese firms is to some extent related to the Chinese cultural tradition, the specific links between compositional capability and Chinese cultural tradition remain largely unspecified (Li \& Peng, 2008; Peng, Li, \& Tian, 2016). 
It is reasonable to assume that compositional capability may be favored by certain cultural contexts, so the deep-level impact of Chinese cultural tradition on the choice and development of compositional capability is worth exploring. ${ }^{2}$ Therefore, this paper aims to answer the following question: How does culture influence the propensity for compositional capability in China?

From the outset, we need to clarify that our assumption or goal is not to claim that compositional capability is confined to Chinese firms or only the context of China. Nevertheless, we believe that it is one of the most salient features of China's economic development, and we also assume that it is more relevant to emerging economies than to advanced economies by default. As Peng (2012) observes, although some strategic behaviors of Chinese firms are consistent with what scholars observe in other countries, the arrival of Chinese firms in the global arena has created some unique challenges to both mainstream research and the practice of management. While we recognize that not all firms in China apply compositional capability, and that some non-Chinese firms have similar capabilities such as frugal innovation or jugaad (Prabhu \& Jain, 2015; Zeschky, Widenmayer, \& Gassmann, 2011), it is common for Chinese firms to rely heavily on compositional capability (Luo \& Child, 2015). From this perspective, we think the Chinese context is an appropriate setting to explore the construct of compositional capability. Nevertheless, we can still draw broad implications from compositional capability beyond the Chinese context.

We argue that the fundamental cultural value of balanced moderation in China

\footnotetext{
${ }^{2}$ We do not assume that our cultural explanation is sufficient for compositional capability because other factors, such as the economic factor of lacking extraordinary resources, also play critical roles.
} 
(“zhongyong” or 中庸) $)^{3}$ drives two mechanisms to support or enable compositional capability: (1) balancing internal learning with external learning and (2) balancing congruity with novelty. Based upon the above two building blocks as the link between culture and capability, we propose an integrative model of compositional capability rooted in the Chinese cultural tradition. By explicating the inherent links between compositional capability and balanced moderation, this paper responds to the calls made by Lu, Tsang, and Peng (2008), Luo and Child (2015), Peng et al. (2016), and Yang, Liu, Gao, and $\mathrm{Li}$ (2012) for more research on identifying the cultural roots of organizational capability.

We contribute to the literature in two ways. First, we posit that compositional capability can be traced back to the Chinese culture of balanced moderation as rooted in the underlying Chinese philosophy of harmony (Zhang \& Ryden, 2002). Specifically, we propose the concrete links between compositional capability and balanced moderation by opening the black box of the latter into two specific constituting values, i.e., knowing oneself and others and unity in diversity. Second, we specify two enabling mechanisms to interconnect the above two sub-values with compositional capability. The two values are only indirectly related to compositional capability, whereas the two mechanisms are directly responsible for the actual development of compositional capability.

\section{Compositional capability}

According to Luo and Child (2015), compositional capability refers to firms' special capabilities in identifying, obtaining, and integrating ordinary resources available in the market and then combining them in a special way to creatively and speedily adapt to

\footnotetext{
${ }^{3}$ We would like to clarify that the notion of "balanced moderation" in this paper is not limited to the text of "zhongyong" in the Book of Rites, but has a broader scope in traditional Chinese philosophy.
} 
market demands. For example, Xiaomi's Mi-Box combines the diverse functions of free HD movies, TV shows, karaoke songs, photos, websites, videos, games, music and other applications to allow users to control Mi-TV via a Mi-phone, play games and music, view photos and watch videos. It is not simply a matter of adding many features or functions to one device, but instead is a sophisticated process of redesigning and reconfiguring multiple elements, including multiple technical platforms and cross-functional interface systems. As Luo and Child (2015) suggest, Xiaomi's overall business model creatively combines Dell's supply chain model, Amazon's Internet channel model, social media's crowd sourcing model, and Facebook's economy of fans. This special capability enables resource-constrained firms to achieve competitive advantages so that firms with insufficient or limited strategic assets (e.g., advanced technology and a well-known brand) can compete successfully against more resourceful rivals (Luo \& Child, 2015). In particular, compositional capability is the foundation for the other two building blocks of the CBV, i.e., compositional competition and compositional offering (Luo \& Child, 2015).

While the concept of compositional capability is Chinese in origin, the idea of combining resources to create advantages for firms is not necessarily specific to China. Indeed, the spirit of hybrid strategy, in our view, is consistent with the spirit of the concept of compositional capability. According to Porter (1980), the failure of a firm in choosing between cost leadership and differentiation was thought to result in inferior performance and lead to a "stuck in the middle" result. However, these firms (especially small and medium-sized enterprises [SMEs]) have neither the capability and scale to support a pure cost leadership strategy nor sufficient resources in advanced technologies, 
brand reputation and original innovation to achieve a pure differentiation strategy (Luo \& Child, 2015; Zeng \& Williamson, 2007). A focus strategy may also not fit the mass markets that most Chinese firms serve, although it may be viable for niche-player SMEs.

Despite Porter's contention about the perils of being "stuck in the middle", other scholars either theoretically or empirically argue firms can pursue a hybrid strategy that includes both cost leadership and differentiation (Hill, 1988; Murray, 1988; Miller \& Dess, 1993; Miller \& Friesen, 1986; Thornhill \& White, 2007). A hybrid strategy not only yields higher returns (relative to pure strategies) via reducing the perils of specialization of cost leadership and differentiation to firms, but also enables them to profit from multiple channels for exploiting potential synergies across different aspects of strategy (Miller, 1992). It is critical for firms (especially resource-constrained firms) to combine and exploit multiple layers of advantages to secure "a defensible balanced position against rivals pursuing pure strategies" (Spanos, Zaralis, \& Lioukas, 2004: 144).

\section{Criticism and defenses of the composition-based view}

The current criticism of the $\mathrm{CBV}$ in general and compositional capability in particular (Volberda \& Karali, 2015) is based on the attempt to reframe compositional capability as consistent with the resource-based view (RBV) and as a special type of dynamic capability, so the $\mathrm{CBV}$ is redundant. Further, this line of criticism implicitly assumes the similarity between the notion of compositional capability and the existing constructs of combinative capability (Kogut \& Zander, 1992; Van de Bosch, Volberda \& De Boer, 1999) and recombinant capability (Carnabuci \& Operti, 2013; Helfat \& Peteraf, 2003; Galunic \& Rodan, 1998). For five reasons, we take issue with the above views.

First, compositional capability for ordinary resources differs fundamentally from the 
combinative capability or recombinant capability for extraordinary resources (sometimes a mix of ordinary and extraordinary resources). To some extent, the RBV is built upon the perspective that the resources to be combined must have the so-called VRIN features, i.e., valuable, rare, inimitable, and non-substitutable (Barney, 1991). In sharp contrast, compositional capability makes no such assumptions; on the contrary, it assumes the opposite (Luo \& Child, 2015).

Second, we recognize that compositional capability is related to Schumpeter's (1934) critical notion of creative destruction to the extent of recombining existing elements is a core mechanism of innovation, but we posit that the two notions differ in at least two aspects. While Schumpeter's notion is silent about the nature of the recombined elements or resources, compositional capability is explicit about the non-VRIN nature of ordinary elements or resources for combination or recombination. Further, while Schumpeter's notion is concerned more with radical innovation, compositional capability is primarily effective for incremental innovation while allowing resource-poor firms to distinguish themselves from resource-rich firms $(\mathrm{Li}, 2018)$ in industries whose boundaries are increasingly blurring (Peng, 2013). For example, Mindray, a leading Chinese healthcare equipment manufacturer, adopted a compositional strategy in its catch-up phase from 1991 to 2000 by emphasizing cheap labor, standard technologies, and key components purchased from the open market (Luo \& Child, 2015).

Third, the criticism of the $\mathrm{CBV}$ in general and compositional capability in particular assumes capability as a set of routines, including dynamic capability as special routines. This view is inconsistent with the argument that dynamic capability must contain some elements to break away from existing routines (Teece, 2007). In other words, a capability 
is dynamic largely due to its potential to disregard and violate existing routines. Hence, while the lower-order ordinary capability is built upon routines, the higher-order dynamic capability cannot be reduced to routines (Teece, 2012; Winter, 2003).

Fourth, we recognize the potential link between compositional capability and dynamic capability, but the two are still distinctive. Dynamic capability refers to the special higher-order ability to transform or update the existing lower-order "ordinary" capabilities (Teece, 2007). In contrast, compositional capability refers to the emergence or birth of lower-order ordinary capabilities out of ordinary (with non-VIRN features) resources before such capabilities can be later transformed (Luo \& Child, 2015), even including the process in which dynamic capability is developed and deployed, particularly with respect to the need to unlearn existing capabilities (Zeng, Simpson, \& Dang, 2017).

Fifth, while the RBV focuses on VRIN resources as the special input in a process model, the CBV emphasizes the transformational process that itself turns ordinary resources into extraordinary outcomes by balancing seemingly opposite elements, including imitation and innovation (Luo \& Child, 2015; Zeng et al., 2017). In sum, we argue that the $\mathrm{CBV}$ represents distinct insights from the RBV and warrants research attention in its own right. We seek to extend the CBV by exploring its cultural roots in a Chinese context, to which we turn next.

\section{Compositional capability and Chinese cultural tradition}

The literature suggests that culture plays a critical role in shaping firms' special capabilities for creativity and innovation by affecting both private cognitive processes and public social norms (Chiu \& Kwan, 2010; De Dreu, 2010; Hofstede, 2007; Morris \& 
Leung, 2010). Culture implies informal routines, which are socially shared expectations and sense-making processes - what everybody conforms to and knows about what everybody conforms to and knows (Zou et al., 2009). Norms can become institutionalized within a group of people to the extent that they come to be performed ritually as an end in themselves (Scott, 1998). While culture cannot strictly determine an individual's capacity for creativity or innovation, it may affect the likelihood of a particular cognitive process being adopted (De Dreu, 2010), and it can influence the cognitive process of generating, selecting, and accepting new ideas both at the individual and the group levels (Chiu \& Kwan, 2010). Further, culture can also moderate the key influence of organizational and social contexts, such as organizational structure and social network, on creativity and innovation (Zhou \& Su, 2010).

In some cultures, people are more willing to take risks and explore the unknown without fear of being ridiculed for coming up with "strange" or "crazy" ideas (Hofstede, 2007), while people in other cultures would be more reluctant to do so (De Dreu, 2010). For example, some studies show that cultures characterized by low power distance, low uncertainty avoidance, and low collectivism are more likely to come up with novel ideas (Erez \& Nouri, 2010; Nakata \& Sivakumar, 1996; Shane, Venkataraman, \& MacMillan, 1995). Comparing the United States with Japan due to the uniqueness of Japanese traditional culture and modern management styles that emphasized consensus building, Japanese firms were more successful in the modification, improvement, and application of existing technologies but "not as successful in the invention or discovery of revolutionary new technologies" (Flynn, 1985:159). In China, where the culture is almost diametrically opposite to Western cultures (House, Hanges, Javidan, Dorfman, \& Gupta, 
2004), people are more motivated to follow instructions, conform to rules or routines, and hide their unique ideas to avoid the social sanctions of deviating from the norm (Erez \& Nouri, 2010). While this suggests that Chinese managers and employees may be less inclined to pursue novel, high-risk ideas, there may well be other Chinese cultural characteristics that have a good fit with compositional capability. As Luo and Tung (2018: 142) specifically suggest, many East Asian firms "have adopted the 'middle way' as their philosophy to formulate strategies, manage organizations, and deal with external partners".

We argue that compositional capability is related to cultural factors rooted in Chinese traditions. Specifically, the underlying logic of compositional capability is consistent with the Chinese philosophy of harmony via embracing and balancing different elements on opposite sides. It is especially critical for firms who are developing and utilizing compositional capability to recognize the salience of accepting and appreciating paradoxical elements as both conflicting and complementary (Li, 2012a, 2016). Next, we explain such links between the Chinese cultural value of balanced moderation and two critical mechanisms to enable compositional capability - balancing internal and external learning and balancing congruity and novelty. This explanation will focus on two unique Chinese cultural values: (1) knowing oneself and others for the first mechanism, and (2) unity in diversity for the second mechanism. The above two links serve as the building blocks for our conceptual model that makes three assumptions. First, behaviors are required to drive the process of transformation from cultural value to organizational capability. Second, these two mechanisms are behavioral in nature as required enablers. Third, behavioral mechanisms serve as the necessary mediators for the transition from the 
two cultural values to compositional capability (see Figure 1 for more detail).

\section{INSERT FIGURE 1}

\section{The traditional value of balanced moderation}

"Middle Kingdom" is the literal translation of "Zhongguo" (中国)—-the Mandarin word for "China". The philosophical basis of the Middle Kingdom relies on an integrated life by balancing extremes (Chen, 2002). At the core of the Chinese philosophical perspective of harmony is balanced moderation (Zhang \& Ryden, 2002). The Chinese value of balanced moderation is composed of two characters in one phrase: "zhong" (中) and “yong” (庸). “Zhong” literally means "avoiding going to extremes" and implies an adequate balance between opposite forces. "Yong" represents "ordinary regularity but practical usefulness". In Chinese culture, moderation means "avoiding going to extremes as well as avoiding falling short" in all situations. Hence, the phrase "zhongyong" (中庸) refers to the general practice of applying the proper balance between opposite elements to all situations, including the most ordinary of everyday issues. The fundamental value of balanced moderation, which is deeply rooted in the Chinese way of thinking, is seen as one of the greatest ideals of daily life in China, penetrating every aspect of society.

Balanced moderation is embedded in China's mainstream philosophies, ideologies and religions (Jullien, 2004; Li, 2012b). The idea of moderation is stressed in the rituals, doctrines, and philosophies of all three major philosophical influences on Chinese culture: Confucianism, Taoism and Buddhism.

The idea of balanced moderation is deeply entrenched in Confucianism, which was 
adopted as the official philosophy of many dynasties and has endured as the basic social and political value system for thousands of years (Yum, 1998). In the classic text The Analects of Confucius (Waley, 2005), Confucius said "as a kind of morality, moderation is the highest one". Balanced moderation in Confucianism encourages people to maintain harmony by avoiding extremes (Chen, 2002). The first Chinese character of balanced moderation, "zhong" in Confucianism, not only refers to the literal meaning of "middle" but also means appropriateness (as opposed to excess). The value of balanced moderation has also been highly stressed in the Confucian text of "zhongyong" (in Li Chi, the Book of Rites).

The core value of balanced moderation is also deeply embedded in Taoism, which advocates that instead of desperately trying to do things by forcing the situation or acting against the flow of nature in the desire to achieve goals, individuals should adopt the idea of “wu wei (inactive action or 无为)". The idea of “wu wei" induces the Chinese to follow "an in-between road, rather than doing something too good or something too bad" (Xing \& Sims, 2011:4), thus cultivating the natural self. The founding father of Taoism, Lao Tzu taught that a person should hide, not overexpose, his or her special capabilities and advantages so that they could be preserved, not attacked or worn down. Hence, Taoist Chinese never seek an extreme state of achievement because to do so would likely trigger a reversal. The core value of balanced moderation encourages Taoist Chinese to restrict themselves from over-doing anything. It is worth mentioning that the other best-known Taoist scholar, Chuang Tzu (369-286 BC), also suggested that "all men know the advantage of being useful, but no one knows the advantage of being useless" (Chuang Tzu, trans. 1891:222). This old maxim resonates with compositional capability by 
encouraging people to turn useless things into useful things by identifying and exploring the value of ordinary resources.

The culture of balanced moderation is also significantly manifested in Buddhism. Notably, the Mahayana Buddhist school of philosophy is called "Madhyamaka" (Ruegg, 1981; Westerhoff, 2009), which means "middling", "medium", or "belonging to the midmost" ("Madhya" is a Sanskrit word meaning "middle"). The core idea of Madhyamaka is the true middle way philosophy that encourages people to avoid the opposite extremes of being and non-being. This idea repeatedly emphasizes that "the truth is about not falling into the extremes; the middle path is away from the two extreme sides". Nagarjuna's writings on the fundamentals of Madhayamaka had a significant impact on the formation of Chinese Buddhism, with various schools regarding him as their founder. Hence, the core value of balanced moderation became strongly embedded in Buddhism in China.

In sum, the idea of balanced moderation is deeply rooted in ancient Chinese culture. The three leading philosophical influences on cultural tradition share a common theme of balanced moderation, which is a highly effective way for firms to manage in the contexts characterized by high uncertainty and ambiguity (Li, 2012b).

\section{Balanced moderation as a cultural driver}

Firms in China are experiencing increasing and accelerating globalization, rapid and often disruptive technological changes, extremely fierce competitive markets, and highly uncertain competitive conditions and government policies. In such a context, a large

group of firms is likely to maintain a holistic and moderate view of development (Peng et al., 2016). For example, the founder of Fotile, a Chinese company specializing in kitchen 
appliances, has explicitly said, "we don't want to fight to be No.1 in the market, we are willing to be No. 2" (Zhang, 2009:146). The president of Hengdian Group-a diversified firm in industries such as electrical and electronics, pharmaceuticals and chemistry, film and tourism - also said publicly, "we don't have to be one of the top 500 companies in the world... we need to consider when we shall do something, and when not to do something" (Hengdian Group News, 2013). The culture of balanced moderation also encourages employees and organizations to tolerate contradictions and even embrace the coexistence of risk and opportunity along with the transition between adverse and favorable situations (Chou, Chu, Yeh, \& Chen, 2014). More importantly, the fundamental value of balanced moderation contains specific values that influence firms' compositional capability by affecting the likelihood and the process of differentiating and integrating ordinary resources in a particular portfolio or configuration with imitative and innovative solutions. We refer to differentiation as the identification and separation of distinctive elements or resources and integration as the portfolio or configuration of such differentiated elements or resources.

Specifically, we focus on two cultural values that constitute the core value of balanced moderation: (1) knowing oneself and knowing others (知已知彼), and (2) unity in diversity (和而不同). The former reflects the content and process of specifying diverse internal and external resources, while the latter highlights the content and process of enabling the diverse resources as more complementary than conflicting in their configuration or portfolio. Hence, differentiation and integration jointly constitute the Chinese traditional ideal of harmony with the traditional value of balanced moderation at its core. We further argue that these two values have salient impacts on the two core 
mechanisms for compositional capability: (1) the effect of knowing oneself and knowing others on the balance between external and internal learning, and (2) the effect of unity in diversity on the balance between congruity and novelty. It is worth noting that the two core mechanisms are also interrelated in multiple ways, which will be elaborated later.

\section{Two core values for compositional capability}

Balancing knowing oneself with knowing others. The fundamental value of balanced moderation is reflected in the specific value of balancing the knowledge about oneself with the knowledge about others. In Tao Te Ching, Lao Tzu notes that "he who knows other men is smart; he who knows himself is wise". However, traditional Chinese philosophy consistently stresses the importance of understanding oneself. For example, Confucius illustrates the process of knowing himself: "at thirty, I stood firm; at forty, I had no doubt; at fifty, I knew the decrees of Heaven". Sun Tzu elaborates the method of knowing oneself: "if a gentleman studies knowledge broadly and examines himself every day, his wisdom will become clear and his conduct will be faultless". That notwithstanding, traditional Chinese philosophy also underlines the significance of knowing others. For instance, Confucius also stresses the importance of knowing others: "I will not be afflicted at men's not knowing me; I will be afflicted that I do not know men". In short, balancing knowing oneself and knowing others can be summarized by the best-known statement from Sun Tzu: "if you know your enemies and know yourself well, you will not be put at risk even in a hundred battles".

The value of knowing oneself and others also reframes the relationship between the subjective and objective elements as only partially separable to allow them to be partially integrated, which is consistent with the perspective of tacit knowledge (Polanyi, 1966; 
Nonaka, 1994). This is related to the Chinese philosophical ontology of "Tian-Ren-He-Yi" (天人合一, the nature-human harmony), in which nature and mankind are partially separable and partially integrative (Peng et al., 2016). It is balanced moderation that makes it possible to identify internal and external resources as inter-connected, interpenetrable, and inter-transformational in a holistic and dynamic configuration $(\mathrm{Li}, 1998$, 2012a, 2016).

Most relevant to our paper is that the value of knowing oneself and others is concerned with the differentiation or separation between diverse elements or resources to identify and specify their distinctive features for different roles, especially those related to diverse resources from multiple external sources. Given the lack of extraordinary resources, including the related lack of absorptive capacity for extraordinary resources, many Chinese firms have to rely more on identifying and combining diverse ordinary resources from multiple and rich external sources to compensate for the lack of extraordinary resources (Luo \& Child, 2005). In other words, Chinese firms substitute the lack of depth in terms of extraordinary resources with the option of breadth in terms of diverse ordinary resources from multiple external sources. As it is related to the other core value, the value of knowing oneself and others provides the salient basis for the value of unity in diversity because the former offers a way to differentiate various elements before they can be integrated later. In other words, compositional capability must contain the ability to identify or specify various elements before such elements can be combined or mixed in any portfolio or configuration.

In sum, we posit that the Chinese traditional view of knowing oneself and others is one of the two values that constitute the fundamental value of balanced moderation, 
which provides the first foundation for the Chinese philosophical ontology of harmony with the value of balanced moderation at its core.

Balancing unity with diversity. The cultural value of balancing unity with diversity — going extremely toward neither pure unity nor pure diversity — is the other core manifestation of balanced moderation. The Chinese believe it is important to organically manage both the differences and the similarities between multiple objects or concepts to handle their links both holistically and dynamically. There are some differences between things with common characteristics, while similar things also tend to preserve some differences. The behavior of pursing unity while preserving diversity is a salient value for harmony with the cultural value of balanced moderation at its core in China (Li, 1998, 2012a, 2016).

More saliently, the value of unity in diversity reframes the relationship between persons and issues not only at the dyadic level but also at the network level (Leung, Brew, Zhang, \& Zhang, 2011; Li, 1998, 2016), which is directly related to the reemerging interest in the complex configuration approach (Fiss, 2007, 2011). Finally, it is balanced moderation that makes diversity more complementary than conflicting, while extreme diversity often results in conflict. In sum, we posit that the Chinese traditional view of unity in diversity is the other core value for balanced moderation, which provides the second foundation for the Chinese philosophy of harmony with the value of balanced moderation at its core.

\section{Two core mechanisms for compositional capability}

The two key values related to the value of balanced moderation are critical, but we still need to specify the enabling mechanisms that connect the two values with 
compositional capability. For that purpose, we evoke the attention-based view of the firm, which suggests that what firms do depends on what issues or perspectives tend to attract managerial attention (Ocasio, 1997). In this sense, we focus on the locus of attention in two dimensions directly related to the two core values of knowing oneself and others and unity in diversity. For knowing oneself and others, particular attention can be placed on the balance between internal and external elements for the development of compositional capability. For unity in diversity, particular attention can be placed on the balance between similar and distinctive elements for the development of compositional capability. In other words, compositional capability can be achieved via balancing attention to internal learning with attention to external learning and balancing attention to similarity for congruity with attention to distinction for novelty. We argue that the above two attention balances can serve as the two enabling mechanisms to transform the two core values into compositional capability.

Balancing internal and external learning. Many Chinese firms, deeply rooted in the core value of knowing oneself and others, are likely to achieve compositional capability via the behavioral mechanism of balancing internal and external learning for the more effective identification and differentiation of diverse elements. On the one hand, a firm focusing only on its own internal elements for learning, primarily from its own experiences, tends to block valuable external sources of information and resources. On the other hand, a firm focusing only on its external elements for learning, primarily from its rivals, may miss the chance to develop its own core competence and unique culture. For instance, firms need to balance the need to absorb new knowledge from external sources with the need to create internal knowledge (Lewin, Massini, \& Peeters, 2011), 
which can also be framed as resource acquisition and resource accumulation for resource structuring (Li, Li, Wang, \& Ma, 2017).

Furthermore, Chinese culture's strong emphasis on interpersonal ties and leadership style makes it "normal" to identify and obtain resources from both internal and external networks (Luo \& Child, 2015). The Book of Rites states that "a superior man honors his virtuous nature and maintains constant inquiry and study. He seeks to carry the knowledge to its breath and greatness, to omit none of the more exquisite and minute points which it embraces, and to raise it to its greatest height and brilliancy, so as to pursue the course of moderation. He cherishes his old knowledge and is continually acquiring new". This argument encourages firms to maintain a balanced portfolio or configuration with existing internal knowledge and emerging external knowledge. In this sense, the value of balanced moderation with the value of knowing oneself and others drives firms to obtain both internal and external elements in a balanced manner via the specific means of internal and external learning, especially about the identification and differentiation of diverse forces. Consequently, firms with such a core value tend to pursue a process of coevolution between internal and external elements.

For instance, Xiaomi's success is largely built on combining knowledge from its internal and external sources, including through reverse engineering, benchmarking, licensing, and adaptive innovation. Xiaomi also enables and helps its users to participate in designing its operating system, since Xiaomi fans can visit the online forum to report bugs, provide feedback, and suggest new solutions (Luo \& Child, 2015). Another example is Galanz, a microwave producer. On the one hand, Galanz is an original equipment manufacturer (OEM) for Panasonic and Toshiba and distributes OEM brands 
though Walmart and Sears. On the other hand, Galanz is also conducting its own original design manufacturing (ODM) and original brand manufacturing (OBM) for both domestic and foreign markets by leveraging its efficient manufacturing facilities, absorbing transformational technologies from the open market, and developing its own new technologies with improved mechanical design, quality, and function.

The learning literature also supports the idea that firms should learn from both their own successes and failures as well as others' successes and failures (Dahlin, Chuang, \& Roulet, 2018; Lant \& Montgomery, 1987; Miller, 1996, Milliken \& Lant, 1991; Millier, 2003). A firm's own successes and failures can provide valuable lessons about what works and what does not work. Further, the successes and failures of rivals can also show what works and what does not work. A firm with ordinary resources can benefit the most from the balance between internal and external learning to leverage its unique strengths against the special weaknesses of its rivals and minimize its unique weaknesses against the special strengths of its rivals, which is the firm-level part of the well-known SWOT analysis.

Most importantly, a firm good at identifying and differentiating its internal and external elements can better leverage both for not only short-term or temporary but also long-term or sustainable, competitive advantages with the necessary attitude and spirit. Such a firm could balance its self-confidence stemming from its strengths with its selfawareness of its weakness. Such a firm can also balance its motive and capability to learn from both the strengths and weaknesses of others. In other words, this is consistent with the notion of wisdom in terms of knowing and doubting (Meacham, 1990), learned ignorance (Chia \& Holt, 2007), and unlearning (Li, 2016; Weick \& Putnam, 2006), which 
is reflected in the unique Chinese approach of "finding the way" or "muddling through" when confronting a context with high volatility, high uncertainty, high complexity, and high ambiguity (Jullien, 2004; Li, 2012b). In sum, we posit that relative to typical Western firms, typical Chinese firms are more likely to adopt the behavioral mechanism of internal-external balancing for learning.

Balancing congruity and novelty. Many Chinese firms deeply rooted in the core value of unity in diversity are more likely to achieve compositional capability via the behavioral mechanism of balancing novelty with congruity for a more effective configuration or portfolio of similar and distinctive elements. On the one hand, the value of unity drives a strong tendency toward congruity to the extent that firms pay attention to behaviors that are congruent with or similar to existing social norms in developing products or services. On the other hand, the value of diversity drives a strong tendency toward novelty to the extent that firms pay attention to novel behaviors that deviate from existing social norms in the process of innovation.

Given the above contrasting tendencies, the unique Chinese value of balancing unity with diversity will inspire many Chinese firms to balance their attention to novelty with their attention to congruity in terms of a moderate amount of attention to similar elements and a moderate amount of attention to distinctive elements in any configuration or portfolio. In this sense, firms tend to pursue both novelty and congruity at moderate levels toward a "proper" balance between imitation and innovation and between incremental and radical innovations as the targeted outcomes of compositional capability. In particular, the Chinese style of innovation is highly distinctive from that of the West, where individualistic values yield a marked preference for novel distinction at the 
expense of congruent similarity (Morris \& Leung, 2010). In a sharp contrast to the cultural value of individualism in the West, the value of balanced moderation in China is rooted in the cultural value of family-based "collectivism" (which is different from conventional collectivism that is community-based and found in countries such as Japan and Korea) (Li, 1998; Redding, 1990; Triandis, 1995).

Specifically, it is common for Chinese firms to configure their resources as a balanced duality with no extreme attention to either novelty or congruity in general and either creativity or usefulness (Morris \& Leung, 2010). In this sense, Chinese firms tend to derive their competitive advantages via a moderate or balanced approach, such as the balances between cost and value (sometimes referred to as the hybrid strategy that some regard disapprovingly as being "stuck in the middle", Merchant, 2014; Porter, 1980) and between competition and cooperation (now often reframed from a positive perspective as co-opetition, see Bengtsson and Kock, 2014). The differentiation between the "stuck in the middle" strategy and the hybrid strategy lies in the manner in which firms frame the combination of low cost and high value: if firms are "torn between" (Miller \& Friesen, 1986: 39) low cost and high value without being committed to either goal, the strategy can be framed as "stuck in the middle"; if firms deliberately commit to the joint pursuit of both goals, the strategy should be regarded as "hybrid" (Merchant, 2014: 294).

Consistent with the above cultural influence toward the balance between congruity and novelty in the process of management, specific customer demands in the Chinese market, especially the mid-end, the low-end, and even the base-of-the-pyramid consumers, share a similar tendency toward such a balance (Luo \& Child, 2015). The value of balanced moderation and the value of unity in diversity may further increase 
consumers' perceived risks associated with extremely novel products or services, so it would be difficult for most mass-market consumers in China to adopt radically novel products or services. In addition, the value of balanced moderation encourages firms to keep a low profile concerning competitive advantages, thus resulting in the tendency for Chinese firms to strive for a moderate (neither extremely asymmetrical nor extremely symmetrical) balance between novelty and congruity as their best option for resource configuration or a business portfolio (Li, 1998, 2016).

In sum, we posit that relative to Western firms, Chinese firms are more likely to adopt the behavioral mechanism of novelty-congruity balancing. It is worth repeating that it is the value of unity in diversity that makes it possible to balance novelty (creativity) and congruity (usefulness) as interconnected, interpenetrable, and intertransformational in a holistic and dynamic configuration or portfolio (Li, 1998, 2012a, 2016).

\section{Discussion}

\section{Contributions}

Two major contributions emerge. First, we have identified one fundamental value with two constituting values as the cultural roots of compositional capability in the context of China. Specifically, the fundamental value of balanced moderation consists of two values, i.e., knowing oneself and others and unity in diversity. While the first value is primarily concerned with differentiation and separation between all specific elements as similar or distinctive at the micro-level of each element, the second value is primarily concerned with the integration and assembly of both distinctive and similar elements at the meso-level of each configuration or portfolio with multiple elements. Such an identification of the cultural roots of compositional capability makes a salient 
contribution to the CBV by embedding it into the cultural and historical context. This contribution answers the call for more contextualized research in general (Li, Leung, Chen, \& Luo, 2012; Li, Sekiguchi, \& Zhou, 2016) and for more research on the link between culture and capability in particular (Luo \& Child, 2015; Lu et al., 2008; Peng et al., 2016; Yang et al., 2012). It is worth repeating that the above cultural values are all rooted in the underlying Chinese philosophy of harmony.

Despite our focus on the deep-rooted link between the Chinese traditional culture and compositional capability, firms in the West and other countries with individualistic values can still develop their own versions of compositional capability and adopt their own versions of compositional strategy. The primary reason for us to focus on the context of Chinese traditional culture is twofold. On the one hand, we want to explore why and how Chinese latecomers can catch up and even potentially leapfrog Western incumbents, thus the need to explain the necessity of compositional capability for Chinese firms. On the other hand, we want to highlight the fact that Chinese culture tends to move toward compositional capability so that we can explore why and how Chinese firms would prefer such a competitive approach, thus the need to explain the desirability of compositional capability for Chinese firms. In this sense, there are both economic and cultural explanations for the strong tendency of Chinese firms toward compositional capability. It is worth repeating that we do not assume that the cultural explanation is sufficient for compositional capability because as mentioned above, other factors (such as the economic factor of lacking extraordinary resources) can also play critical roles. It is also interesting to note that Japanese and Korean firms historically followed a trajectory or path from imitation to innovation in their early days similar to the one that Chinese firms 
are following now (Bolton, 1993; Kim, 1997; Westney, 1987). Although both Japanese and Korean firms shared similar cultural and economic contexts with Chinese firms, Chinese firms as a group seem to have a much stronger tendency toward compositional capability due to their stronger cultural values and more acute economic challenges.

Second, we have specified two enabling mechanisms to interconnect the above two values with compositional capability. In other words, the two values are only indirectly related to compositional capability, whereas the two mechanisms are directly responsible for the actual development of compositional capability. Specifically, the behavioral mechanism of balancing internal and external learning serves as the primary mediator between the cultural value of knowing oneself and others and the target outcome of compositional capability, while the behavioral mechanism of balancing novelty with congruity serves as the primary mediator between the cultural value of unity in diversity and the target outcome of compositional capability. In this sense, relative to typical Western firms, Chinese firms may be more likely to adopt the behavioral mechanism of internal-external balancing for learning and the behavioral mechanism of noveltycongruity balancing. The identification of such behavioral mechanisms can contribute to the CBV by providing specific explanations about where and how compositional capability is being developed above and beyond the cultural and historical context. It is worth noting that behavioral mechanisms are required as enabling mediators for the transformation from cultural value to organizational capability.

As Colquitt and George (2011:434) argued in an editorial of Academy of Management Journal argued, "the innovation literature typically paints innovation as the result of capital-intensive research and development efforts. How, then, can we explain 
emergent innovations that have low capital intensity, severely restricted research and development spending, yet still create value"? This line of research is truly worth much more attention.

\section{Limitations and future research directions}

This paper has two main limitations. First, ours is a purely conceptual argument, and future work can build on what we have done and test our model empirically (see Peng et al. [2016] for an example). Second, China is our main context for developing the theoretical framework. However, culture is strongly embedded within the national context, and our context may restrain the boundary of cultural analysis. We hope that our preliminary ideas could stimulate more studies to enrich this literature in the future.

For instance, future research can fruitfully explore the role of culture in encouraging firm growth in other emerging economies. Transitional markets in the Western hemisphere, such as Brazil, obviously have different cultural roots. Further, in the case of other Asian transitional markets, such as India, the role of culture in a specific context remains an open question and scholars are calling for more research on the impact of culture on firms' development in India (Nair, Guldiken, Fainshmidt, \& Pezeshkan, 2015). Given the traditional roots of Buddhism in India and the references to moderation in Indian sacred texts such as the Bhagavad Gita, there may be some similarities with China that await discovery. However, the significant historical divergence related to colonial influences may also result in many distinctive features. As we mentioned earlier, similar to compositional capability, some concepts such as frugal innovation or "jugaad" also stress the limited purchasing resources of consumers in the market and are characterized by the goal of being "good enough" at a radically low cost by achieving great efficiency 
(Nair et al., 2015). Hence, in comparing different settings (e.g., China and India), one particular focus can be the distinctive capabilities evoked in developing different types of innovations most salient in the emerging economies, such as compositional, frugal, or inclusive innovations.

It is also possible for non-Chinese firms to benefit from compositional capability and the CBV, even though such issues originated in China. This is similar to the case of Chinese firms effectively learning from the West even though modern technologies were originally derived from the West and are often rooted in Western cultural values. The reverse is also true for the West to learn from the East (Li, 2012b). As Prashantham, Eranova, and Couper (2018) argue, it would be naive to assume that traditional Chinese norms would be totally unfamiliar to the West. For example, the Western notion of paradoxical thinking has been integrated with the Chinese indigenous frame of yin-yang balancing for a valuable contribution to the various issues of management such as formalinternal interface (Lin, Lu, Li, \& Liu, 2015), co-opetition (Chen, 2008), leadership behavior (Zhang, Walder, Han, \& Li, 2015), and organizational trust (Li, 2008; Smith \& Lewis, 2011). In our case, the idea of moderation has been mentioned in ancient Greek philosophy, especially that of Aristotle, who referred to it as the golden means to achieve a proper balance between two extremes (Aristotle, 1956). Hence, more research on the reflection or application of Chinese theories of management, firm growth, and innovation will provide more cross-fertilization between the East and the West for a truly geocentric body of knowledge and practice (Chen, 2014; Chen \& Miller, 2011; Li, 2012b; March, 2005; Peng, Lebedev, Vlas, Wang, \& Shay, 2018). We strongly suggest this line of research as one of the most fruitful in the future. 
Furthermore, the nature of compositional capability is a double-edged sword. We have not only mentioned the positive benefits of compositional capability and the CBV, but also their limitations. The current framing of compositional capability in particular and the $\mathrm{CBV}$ in general is more concerned with incremental or path-dependent exploitation than with radical or path-breaking exploration. For that reason, we may incorporate new elements into the conceptualization of compositional capability and the CBV in future studies. For instance, the critical notion of entrepreneurial bricolage (Baker \& Nelson, 2005) can be evoked to enrich compositional capability and the CBV. This notion has been expanded into the Chinese construct of creative bricolage in terms of combining ordinary and sub-standard (lower than ordinary) resources in a radically novel configuration or portfolio. It is also worth noting that the need for a paradigm shift from ordinary resources (also imitative innovation with the breadth of ordinary resources) to extraordinary resources (also original innovation with the depth of extraordinary resources) should be examined in depth in the future. In this aspect, a longitudinal and historical case study is necessary. It is critical for future research to pay more attention to the perspective of yin-yang balancing to more effectively explain why and how to accept and appreciate paradoxes in management in general and compositional capability in particular because the most challenging issues in the domain of management tend to be paradoxical in nature (Chen, 2002; Li, 1998, 2012a, 2016; Schad, Lewis, Raisch, \& Smith, 2016).

Finally, as Peng et al. (2016) suggest, Eastern cultural, philosophical and intellectual traditions can be a rich source of inspiration for management research. Our efforts and discussion of moderation as the cultural roots of compositional capability are merely a 
first step to tap into such a potentially rich literature, and future researchers are encouraged to engage in more exploration. In particular, the interplay between cultural and economic factors can provide a more holistic and dynamic explanation for diverse patterns of innovation across various national and regional contexts.

\section{Conclusion}

In conclusion, we note that our work holds significance as Chinese firms "find the way" in terms of transitioning from cost-led to innovation-based competitiveness. The CBV is a potentially valuable perspective from which to better understand how emerging market firms in general and Chinese firms in particular can create and capture value from ordinary resources. We believe that the notion of zhongyong (balanced moderation) provides a powerful cultural basis for understanding the propensity of many Chinese firms to develop high-level compositional capability. As such, we enthusiastically anticipate the emergence of an exciting body of research on firm growth based on ordinary resources in China and other emerging markets and hope that our contribution stimulates further research building on Luo and Child's (2015) seminal work on compositional capability. 
Figure 1. The Cultural Roots of Compositional Capability

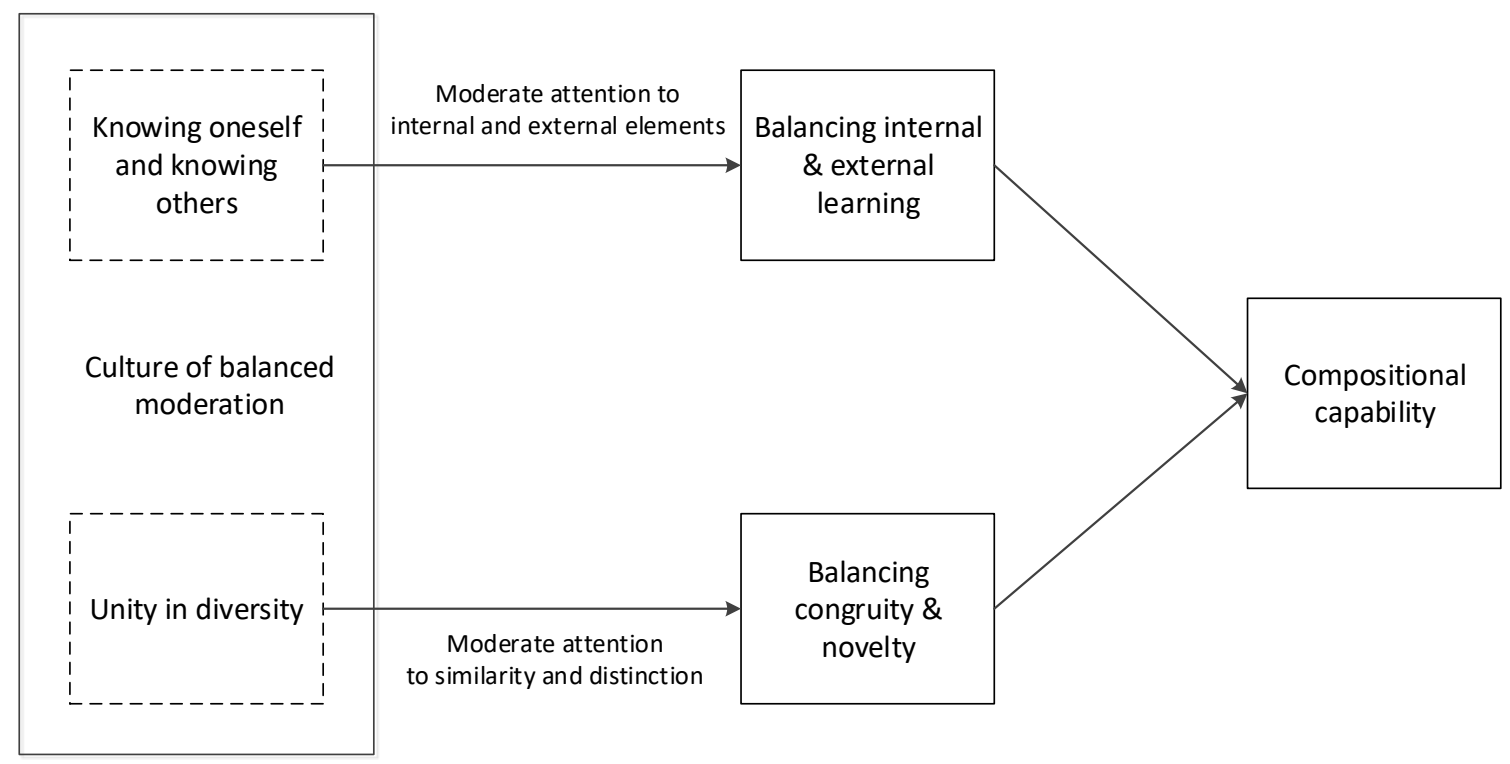




\section{References}

Aristotle. 1956. The Nicomachean Ethics (H. Rackham, Text and Trans.). Cambridge: Harvard University Press.

Barney J. B. 1991. Firm resources and sustained competitive advantage. Journal of Management, 17 (1): 99-120.

Baker, T., \& Nelson, R. E. 2005. Creating something from nothing: Resource construction through entrepreneurial bricolage. Administrative Science Quarterly, 50 (3): 329-366.

Bengtsson, M., \& Kock, S. 2014. Coopetition-Quo vadis? Past accomplishments and future challenges. Industrial Marketing Management, 43 (2): 180-188.

Bolton, M. K. 1993. Imitation versus innovation: Lessons to be learned from the Japanese. Organizational Dynamics, 21 (3): 30-45.

Carnabuci, G., \& Operti, E. 2013. Where do firms' recombinant capabilities come from? Intraorganizational networks, knowledge, and firms' ability to innovate through technological recombination. Strategic Management Journal, 34 (13): 1591-1613.

Chia, R., \& Holt, R. 2007. Wisdom as learned ignorance: Integrating East-West perspectives. In E. H. Kessler, \& J. B. Bailey (Eds.), Handbook of Organizational and Managerial Wisdom: 505-527. Thousand Oaks, CA: Sage.

Chiu, C. Y., \& Kwan, L. Y. 2010. Culture and creativity: A process model. Management and Organization Review, 6 (3): 447-461.

Chen, M.-J. 2002. Transcending paradox: The Chinese "middle way" perspective. Asia Pacific Journal of Management, 19 (2-3): 179-199.

Chen, M.-J. 2008. Reconceptualizing the competition-cooperation relationship: a transparadox perspective. Journal of Management Inquire, 17 (4): 288-304.

Chen, M.-J. 2014. Becoming ambicultural: A personal quest, and aspiration for organizations. Academy of Management Review, 39 (2): 119-137.

Chen, M.-J., \& Miller, D. 2011. The relational perspective as a business mindset: Managerial implications for East and West. Academy of Management Perspectives, 25 (3): 6-18.

Chiu, C. Y., \& Kwan, L. Y. Y. 2010. Culture and creativity: A process model. Management and Organization Review, 6 (3): 447-461.

Chou, L. F., Chu, C. C., Yeh, H. C., \& Chen, J. 2014. Work stress and employee well-being: The critical role of zhongyong. Asian Journal of Social Psychology, 17 (2): 115-127.

Chuang Tzu. 1891. The writings of Kwang-Sze (J. Legge, Trans.). In J. Legge (Eds.) The sacred books of China: The texts of Taoism: 125-392. London: Oxford University Press. (Original work published ca. 300 BC).

Colquitt, J. A, \& George, G. 2011. From the editors: Publishing in AMJ - part 1: topic choice. Academy of Management Journal, 54 (3): 432-435.

Dahlin, K. B., Chuang, Y. T., \& Roulet, T.J. 2018. Opportunity, motivation, and ability to learn from failures and errors: Review, synthesis, and ways to move forward. Academy of Management Annals, 12 (1): 252-277.

De Dreu, C. K. 2010. Human creativity: Reflections on the role of culture. Management and Organization Review, 6 (3): 437-446.

Erez, M., \& Nouri, R. 2010. Creativity: The influence of cultural, social, and work contexts. Management and Organization Review, 6 (3): 351-370. 
Fiss, P. C. 2007. A set-theoretic approach to organizational configurations. Academy of Management Review, 32 (4): 1180-1198.

Fiss, P. C. 2011. Building better causal theories: A fuzzy set approach to typologies in organization research. Academy of Management Journal, 54 (2): 393-420.

Flynn, D. M. 1985. Organizational and environmental effects on innovation: A comparison of two countries. Asia Pacific Journal of Management, 2 (3):150-163.

Galunic, D. C., \& Rodan, S. 1998. Resource recombinations in the firm: Knowledge structures and the potential for Schumpeterian innovation. Strategic Management Journal, 19 (12): 1193-1201.

Helfat, C. E., \& Peteraf, M. A. 2003. The dynamic resource-based view: Capability lifecycles. Strategic Management Journal, 24 (10): 997-1010.

Hengdian Group News, 2013. The harmonious development of corporate culture and the influence of zhongyong (in Chinese).

http://www.hengdian.com/phone/zhuantidot_7240.html, Accessed Jun. 6, 2018.

Hill, C. W. 1988. Differentiation versus low cost or differentiation and low cost: A contingency framework. Academy of Management Review, 13 (3): 401-412.

Hofstede, G. 2007. Asian management in the 21 st century. Asia Pacific Journal of Management, 24 (4): 411-420.

House, R. J., Hanges, P. J., Javidan, M., Dorfman, P. W., \& Gupta, V. 2004. Culture, Leadership, and Organizations: The GLOBE Study of 62 Societies. Thousand Oaks: Sage publications.

Jullien, F. 2004. A Treatise on Efficacy: Between Western and Chinese Thinking. Honolulu: University of Hawaii Press (with J. Lloyd as the Translator).

Keane, M. 2007. Created in China: The Great New Leap Forward. London: Routledge.

Kim, L. 1997. Imitation to Innovation: The Dynamics of Korea's Technological Learning. Brighton: Harvard Business Press.

Kogut, B., \& Zander, U. 1992. Knowledge of the firm, combinative capabilities, and the replication of technology. Organization Science, 3 (3): 383-397.

Koh, A. T. 2000. Linking learning, knowledge creation, and business creativity: A preliminary assessment of the East Asian quest for creativity. Technological Forecasting and Social Change, 64 (1): 85-100.

Lant, T. K., \& Montgomery, D. B. 1987. Learning from strategic success and failure. Journal of Business Research, 15 (6): 503-517.

Leung, K., Brew, F. P., Zhang, Z. X., \& Zhang, Y. 2011. Harmony and conflict: A crosscultural investigation in China and Australia. Journal of Cross-Cultural Psychology, 42 (5): 795-816.

Lewin, A.Y., Massini, S., \& Peeters, C. 2011. Microfoundations of internal and external absorptive capacity routines. Organization Science, 22 (1): 81-98.

Li, P. P. 1998. Towards a geocentric framework of organizational form: A holistic, dynamic and paradoxical approach. Organization Studies, 19 (5): 829-861.

Li, P. P. 2008. Toward a geocentric framework of trust: An application to organizational trust. Management and Organization Review, 4 (3): 413-439.

Li, P. P. 2012a. Toward an integrative framework of indigenous research: The geocentric implications of Yin-Yang balance. Asia Pacific Journal of Management, 29 (4): 849-872. 
Li, P. P. 2012b. Exploring the unique roles of trust and play in private creativity: From the complexity-ambiguity-metaphor link to the trust-play-creativity link. Journal of Trust Research, 2 (1): 71-97.

Li, P. P. 2016. Global implications of the indigenous epistemological system from the East: How to apply Yin-Yang balancing to paradox management. Cross Cultural \& Strategic Management, 23 (1): 42-77.

Li, P. P., Leung, K., Chen, C. C., \& Luo, J.-D. 2012. Indigenous research on Chinese management: What and how. Management and Organization Review, 8 (1): 7-24.

Li, P. P., Sekiguchi, T., \& Zhou, K. 2016. The emerging research on indigenous management in Asia. Asia Pacific Journal of Management, 33 (3): 583-594.

Li, X. 2018. How emerging market resource-poor firms compete and outcompete advanced country resource-rich rivals: An asymmetry reversing theory. Cross Cultural \& Strategic Management, 25 (3), 538-544.

Li, Y., \& Peng, M. W. 2008. Developing theory from strategic management research in China. Asia Pacific Journal of Management, 25 (3): 563-572.

Li, Y., Li, P. P., Wang, H. F., \& Ma, Y. C. 2017. How do resource structuring and strategic flexibility interact to shape radical innovation? Journal of Product Innovation Management, 34 (4): 471-491.

Legge, J., Trans. 1967. Li Chi: Book of Rites. New York: University Books.

Lin, D. M., Lu, J. Y., Li, P. P., \& Liu, X. H. 2015. Balancing formality and informality in business exchanges as a duality: a comparative case study of returnee and local entrepreneurs in China. Management and Organization Review, 11 (2): 315-342.

Luo, Y., \& Child, J. 2015. A composition-based view of firm growth. Management and Organization Review, 11 (3): 379-411.

Luo, Y., \& Tung, R. 2018. A general theory of springboard MNEs. Journal of International Business Studies, 49, 129-152.

Lu, Y., Tsang, E. W., \& Peng, M. W. 2008. Knowledge management and innovation strategy in the Asia Pacific: Toward an institution-based view. Asia Pacific Journal of Management, 25 (3): 361-374

March, J. G. 2005. Parochialism in the evolution of a research community: The case of organization studies. Management and Organization Review, 1 (1): 5-22.

Meacham, J. A. 1990. The loss of wisdom. In R. J. Sternberg (Ed.), Wisdom, its Nature, Origins, and Development (pp. 181-212). Cambridge: Cambridge University Press.

Merchant, H. 2014. Configurations of governance structure, generic strategy, and firm size: opening the black box of value creation in international joint ventures. Global Strategy Journal, 4 (4): 292-309.

Meyer, M. W. 2008. No Free Lunch: Dilemmas of Product Quality in China. Management and Organization Review, 4 (2): 315-322.

Miller, D. 1992. Environmental fit versus internal fit. Organization Science, 3 (2): 159-178.

Miller, D. 1996. Configurations revisited. Strategic Management Journal, 17 (7): 505-512.

Miller, D. 2003. An asymmetry - based view of advantage: towards an attainable sustainability. Strategic Management Journal, 24 (10): 961-976.

Miller, A., \& Dess, G. G. 1993. Assessing Porter's (1980) model in terms of its generalizability, accuracy and simplicity. Journal of Management Studies, 30 (4): 553 - 
585.

Miller, D., \& Friesen, P. H. 1986. Porter's (1980) generic strategies and performance: an empirical examination with American data: part I: testing Porter. Organization Studies, 7 (1): $37-55$.

Milliken F. J. \& Lant T. K. 1991. The impact of an organization's recent performance history on strategic persistence and change: The role of managerial interpretations. In

Shrivastava P., Huff A., \& Dutton J. Advances in Strategic Management, vol. 7: 129-156. Greenwich: JAI Press.

Morris, M. W., \& Leung, K. 2010. Creativity East and West: Perspectives and parallels. Management and Organization Review, 6 (3): 313-327.

Murray, A. I. 1988. A contingency view of Porter's "generic strategies". Academy of Management Review, 13 (3): 390-400.

Nakata, C., \& Sivakumar, K. 1996. National culture and new product development: An integrative review. The Journal of Marketing, 60 (1): 61-72.

Nair, A., Guldiken, O., Fainshmidt, S., \& Pezeshkan, A. 2015. Innovation in India: A review of past research and future directions. Asia Pacific Journal of Management, 32 (4): 925958.

Nonaka, I. 1994. A dynamic theory of organizational knowledge creation. Organization Science, 5 (1): 14-37.

Ocasio, W. 1997. Towards an attention-based view of the firm. Strategic Management Journal, 18(S1): 187-206.

Peng, M. W. 2012. The global strategy of emerging multinationals from China. Global Strategy Journal, 2 (2): 97-107.

Peng, M. W. 2013. Global Strategy, $3^{\text {rd }}$ ed. Boston: Cengage Learning.

Peng, M. W., \& Heath, P. S. 1996. The growth of the firm in planned economies in transition: Institutions, organizations, and strategic choice. Academy of Management Review, 21 (2): 492-528.

Peng, M. W., Lebedev, S., Vlas, C. O., Wang, J. C., \& Shay, J. S. 2018. The growth of the firm. Asia Pacific Journal of Management, 35(4): 829-857.

Peng, M. W., Lee, S. H., \& Wang, D. Y. 2005. What determines the scope of the firm over time? A focus on institutional relatedness. Academy of Management Review, 30 (3): 622633.

Peng, M. W., Li, Y., \& Tian, L. 2016. Tian-ren-he-yi strategy: An Eastern perspective. Asia Pacific Journal of Management: 33 (3): 695-722

Porter, M.E, 1980. Competitive Strategy, New Work: Free Press.

Polanyi, M. 1966. The logic of tacit inference. Philosophy, 41 (155): 1-18.

Prabhu, J., \& Jain, S. 2015. Innovation and entrepreneurship in India: Understanding jugaad. Asia Pacific Journal of Management, 32 (4): 843-868.

Prashantham, S., Eranova, M., \& Couper, C. 2018. Globalization, entrepreneurship and paradox thinking. Asia Pacific Journal of Management, 35 (1): 1-9.

Priem, R. L., \& Butler, J. E. 2001. Tautology in the resource-based view and the implications of externally determined resource value: Further comments. Academy of Management Review, 26 (1): 57-66.

Redding, S. G. 1990. The Spirit of Chinese Capitalism. New York: De Gruyter. 
Ruegg, D. S. 1981. The Literature of the Madhyamaka School of Philosophy in India. Wiesbaden: Otto Harrassowitz.

Schad, J., Lewis, M. W., Raisch, S., \& Smith, W. K. 2016. Paradox research in management science: Looking back to move forward. Academy of Management Annals, 10 (1): 5-64.

Schumpeter, J. A. 1934. The Theory of Economic Development: An Inquiry into Profits, Capital, Credit, Interest, and the Business Cycle. Cambridge: Harvard University Press.

Scott, J. C. 1998. Seeing Like a Atate: How Certain Schemes to Improve the Human Condition have Failed. New Haven: Yale University Press.

Shane, S., Venkataraman, S., \& MacMillan, I. 1995. Cultural differences in innovation championing strategies. Journal of Management, 21 (5): 931-952.

Smith, W. K. \& Lewis, M. W. 2011. Toward a theory of paradox: a dynamic equilibrium model of organizing. Academy of Management Review, 36 (2): 381-403.

Spanos, Y. E., Zaralis, G. \& Lioukas, S. 2004. Strategy and industry effects on profitability: evidence from Greece. Strategic Management Journal, 25 (2): 139-165.

Teece, D. J. 2007. Explicating dynamic capabilities: the nature and microfoundations of (sustainable) enterprise performance. Strategic Management Journal, 28 (13): 13191350.

Teece, D. J. 2012. Dynamic capabilities: Routines versus entrepreneurial action. Journal of Management Studies, 49 (8): 1395-1401.

Thornhill, S., \& White, R. E. 2007. Strategic purity: A multi-industry evaluation of pure vs. hybrid business strategies. Strategic Management Journal, 28 (5): 553-561.

Triandis, H. C. 1995. Individualism and Collectivism, New York: Westview Press.

Volberda, H. W., \& Karali, E. 2015. Reframing the compositional capability: a resource-based view on 'a composition-based view of firm growth'. Management and Organization Review, 11 (3): 419-426.

Van Den Bosch, F. A., Volberda, H. W., \& De Boer, M. 1999. Coevolution of firm absorptive capacity and knowledge environment: Organizational forms and combinative capabilities. Organization Science, 10 (5): 551-568.

Waley, A. 2005. The Analects of Confucius. London: Psychology Press.

Weick, K. E. \& Putnam, T. 2006. Organizing for mindfulness: Eastern wisdom and Western knowledge. Journal of Management Inquiry, 15 (3): 1-13.

Westney, D. E., 1987. Imitation and Innovation: The Transfer of Western Organizational Patterns to Meiji Japan. Cambridge: Harvard University Press.

Westerhoff, J. 2009. Nagarjuna's Madhyamaka: A philosophical introduction. Oxford: Oxford University Press.

Winter, S. G. 2003. Understanding dynamic capabilities. Strategic Management Journal, 24 (10): 991-995.

Xing, Y., \& Sims, D. 2012. Leadership, Daoist Wu Wei and reflexivity: Flow, self-protection and excuse in Chinese bank managers' leadership practice. Management Learning, 43 (1): $97-112$.

Yang, J., Liu, H., Gao, S., \& Li, Y. 2012. Technological innovation of firms in China: Past, present, and future. Asia Pacific Journal of Management, 29 (3): 819-840.

Yum, J. O. 1988. The impact of Confucianism on interpersonal relationships and communication patterns in East Asia. Communications Monographs, 55 (4): 374-388. 
Zeschky, M., Widenmayer, B., \& Gassmann, O. 2011. Frugal innovation in emerging markets. Research-Technology Management, 54 (4): 38-45.

Zeng, J., Simpson, C., \& Dang, B. L. 2017. A process model of dynamic capability development: Evidence from the Chinese manufacturing sector. Management and Organization Review, 13 (3): 643-673.

Zeng, M., \& Williamson, P. J. 2007. Dragons at Your Door. Cambridge: Harvard Business School Press.

Zhang, H., 2009. Overturn: The Survival Strategy of SMEs (in Chinese). Beijing: Tsinghua University Press.

Zhang, D., \& Ryden, E. 2002. Key concepts in Chinese philosophy. New Haven: Yale University Press.

Zhang, Y., Waldman, D., Han, Y. L. \& Li, X. B. 2015. Paradoxical leader behavior in people management: antecedents and consequences. Academy of Management Journal, 58 (2): 538-566.

Zhou, J., \& Su, Y. 2010. A missing piece of the puzzle: The organizational context in cultural patterns of creativity. Management and Organization Review, 6 (3): 391-413.

Zou, X., Tam, K.-P., Morris, M. W., Lee, S.-L., Lau, I. Y.-M., \& Chiu, C.-Y. 2009. Culture as common sense: perceived consensus versus personal beliefs as mechanisms of cultural influence. Journal of Personality and Social Psychology, 97 (4): 579.

Zhu, Y., Wittmann, X., \& Peng, M. W. 2012. Institution-based barriers to innovation in SMEs. Asia Pacific Journal of Management, 29 (4): 1131-1142. 